\title{
Electrosynthesis, Characterization and Electrocatalytic Behaviour of Organic-Metal Thin-Films Based on 2,2'-Bithiophene-5-carboxylic Acid and Metal Ions
}

\author{
Naima Maouche ${ }^{1 *}$, Belkacem Nessark ${ }^{1}$, Saloua Chelli², Salah Aeiyach ${ }^{2}$, Idriss Bakas ${ }^{2}$ \\ ${ }^{1}$ Département de Génie des Procédés, Faculté de Technologie, Université de Sétif, Sétif, Algeria \\ ${ }^{2}$ Laboratoire Interfaces, Traitements, Organisation et Dynamique des Systèmes, Université Paris, \\ Paris, France \\ Email: "nmaouche@univ-setif.dz
}

Received November 8, 2013; revised December 14, 2013; accepted December 21, 2013

Copyright (c) 2014 Naima Maouche et al. This is an open access article distributed under the Creative Commons Attribution License, which permits unrestricted use, distribution, and reproduction in any medium, provided the original work is properly cited. In accordance of the Creative Commons Attribution License all Copyrights (C) 2014 are reserved for SCIRP and the owner of the intellectual property Naima Maouche et al. All Copyright @ 2014 are guarded by law and by SCIRP as a guardian.

\begin{abstract}
2,2'-Bithiophene-5-carboxylic acid (BTA) thin-films on platinum (Pt) electrodes were electrochemically prepared in acetonitrile solution containing $0.1 \mathrm{M}$ tetrabutylammonium perchlorate (TBAP) and 0.05 M BTA. These films were complexes with several metal ions such as $\mathrm{Cu}^{2+}, \mathrm{Ag}^{+}$and $\mathrm{Co}^{2+}$. Their structural characteristics were compared with those of powder complexes chemically prepared from BTA and the corresponding metal ion. IR and XPS techniques reveal that the film complexes with metal ions have the same structures as the corresponding powder complexes. The electrocatalytic activity of BTA film-metal ions has been investigated toward ascorbic acid (AA) oxidation and compared to that obtained on a free BTA film. BTA film-metal ions exhibit good catalytic proprieties and better detection of AA than a free BTA film. This new propriety allows these films to be used as electrochemical sensors. This electronic document is a "live" template. The various components of your paper [title, text, heads, etc.] are already defined on the style sheet, as illustrated by the portions given in this document.
\end{abstract}

\section{KEYWORDS}

\section{2,2'-Bithiophene-5-carboxylic Acid; Metal Ions; Cyclic Voltammetry; IR and XPS; Electrocatalytic Activity;} Ascorbic Acid

\section{Introduction}

Thiophene and its derivatives can be easily polymerized electrochemically or chemically to give conducting polymers with a range of useful properties that make these materials interesting candidates for a variety of potential applications [1,2], such as electro-chromic and electronic devices, electrical energy storage in rechargeable batteries [3] and electrochemical sensors [4], owing to their high chemical stability in air, their ease of preparation and the ability of controlling the doping level. However, conducting polymer systems do not have any intrinsic electrocatalytic activity, and they have been used as host matrices for different chemical species such as metal par-

\footnotetext{
${ }^{*}$ Corresponding author.
}

ticles [5], complex ions [6] and enzymes [7], through which these systems acquire catalytic activity.

In recent years, there has been a growing interest in conducting polymer-metal systems $[8,9]$, where the metal is directly attached to the $\pi$-conjugated backbone, and has the ability to access a continuum of redox states afforded by metal-polymer cooperativity [9].

The incorporation of metal ions into organic conducting polymers offers potential in the area of organic-inorganic hybrid materials. Polyalkynyl platinum(II) complexes were the first materials prepared in this field [10]. In general, a wide variety of metallic ions can be included by incorporation into conducting polymers. If these ions are catalytically or electrocatalytically active, new composite materials can be obtained, whose proper- 
ties will be determined not only by the catalytically active ions, but also by the conducting polymer matrix [11]. This incorporation of dispersed ions into the conducting polymer matrix has two fundamentally different consequences: 1) the polymer structure becomes more porous and spongy, and eventually even at low ion concentrations, facilitates the transport processes accompanying the intrinsic redox process of the polymer; 2) a novel composite material is obtained where the properties are influenced by both components [12].

The oxidation reaction of ascorbic acid (AA) was widely tested on various modified electrodes [13-17]. The role of the AA is known for its properties and its use as an antioxidant agent in foods and drinks, and it is also important for therapeutic purposes and biological metabolism. The determination of AA is a subject of considerable interest and with the use of simple, accurate and advantageous methods. Among of them, the electrochemical determination method is very accurate with high selectivity and best sensitivity. It is recognized as one of the most approaches for the separation of biological compounds such as ascorbic acid and dopamine [18-20]. Therefore, this advantage has a significant attraction in biological and electrochemical research.

With the aim of developing more efficient and novel organic-inorganic hybrid materials to improve their electrocatalytic properties, we were interested here in preparing materials based on 2,2'-bithiophene-5-carboxylic acid (BTA) (Schema 1(a)) and metal ions such as $\mathrm{Cu}^{2+}$, $\mathrm{Ag}^{+}$and $\mathrm{Co}^{2+}$ that displayed electrocatalytic properties toward ascorbic acid oxidation (AA). BTA is selected for this study because: 1) it has an electroactive functional group (carboxylate group) able to coordinate to metal ions leading to complex materials; 2) the electro-oxidation of BTA leads to the formation of thin films on the electrodes. The BTA films chemically treated with metal ion solutions can be used as electrodes for the electrocatalytic oxidation of AA. The complex materials (film or powder form) were characterized by XPS and IR spectroscopy.

\section{Experimental}

\subsection{Materials}

All chemical products and solvents (2,2'-bithiophene-5carboxylic acid (BTA) (Acros organics); copper chloride $\mathrm{CuCl}_{2} \cdot 2 \mathrm{H}_{2} \mathrm{O}$ (Aldrich), cobalt chloride $\left(\mathrm{CoCl}_{2}\right)$ and silver nitrate $\left(\mathrm{AgNO}_{3}\right)$ (Fluka) and acetonitrile (Prolabo), were analytical grade and were used without further purification.

\subsection{Synthesis of BTA-Cu${ }^{2+}$ Complex}

The complex was prepared following the procedure described in the literature [21]. BTA (50 mg, $0.39 \mathrm{mmol}$ )

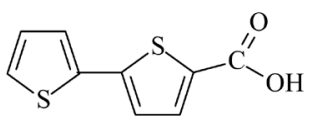

(a)

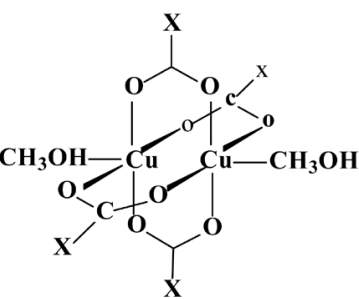

(b)
Schema 1. (a) Schematic representation of the structure of BTA monomer used as ligand. (b) Proposed structure of BTA-Cu complex, with $\mathrm{X}=$ bithiophene.

was dissolved in methanol $(0.8 \mathrm{~mL})$ and $\mathrm{NaOH}(15.6 \mathrm{mg}$, $0.39 \mathrm{mmol}$ ) was added to this solution. After $30 \mathrm{~min}$ stirring, $\mathrm{CuCl}_{2} \cdot 2 \mathrm{H}_{2} \mathrm{O}(26.1 \mathrm{mg}, 0.19 \mathrm{mmol})$ in methanol $(0.5$ $\mathrm{mL}$ ) was added dropwise. The reaction mixture was stirred for an additional $30 \mathrm{~min}$. The green solution was filtered, washed with methanol several times and dried at $50^{\circ} \mathrm{C}$ in vacuum.

\subsection{Electrosynthesis of BTA-M Films}

Thin films of BTA were first prepared electrochemicaly (cyclic voltammetry or chronoampremetry) in solution of $\mathrm{CH}_{3} \mathrm{CN} / \mathrm{TBAP} 0.1 \mathrm{M}$, containing $5 \times 10^{-2} \mathrm{M}$ of BTA, then the film was rinsed with acetone to remove all traces of monomer and transferred in aqueous metallic solutions $(\mathrm{M}=\mathrm{Cu}, \mathrm{Co}, \mathrm{Ag})$ for concentration of $10^{-2} \mathrm{M}$ each one for 10 min separately.

\subsection{Measurements}

Electrochemical measurements were carried out using potentiostat/galvanostat type EG \& G Princeton Applied Research model 273 under Chem software, in three electrode and a one-compartment cell. In most of our experiments the working electrode was a platinum $(\mathrm{Pt})$ disc $0.03 \mathrm{~cm}^{2}$ in area. The counter-electrode was a steel grid and the reference was a conventional saturated aqueous potassium chloride-calomel electrode (SCE). The working electrode was polished before each experiment by cloth polishing with $0.1 \mu \mathrm{m}$ alumina slurry, and rinsed with acetone and ethanol. The supported electrolyte was $0.1 \mathrm{M}$ tetrabutylammonium perchlorate (TBAP) dissolved in argon-purged acetonitrile.

Infrared spectra of the complex and its precursor in the form of pressed $\mathrm{KBr}$ pellets were obtained on a Nicolet Magna-860 Fourier transform infrared spectrometer.

XPS spectra were recorded using a Thermo VG ESCALAB 250 system equipped with a micro-focused, monochromatic Al $\mathrm{K} \alpha$ X-ray source $(1486.6 \mathrm{eV})$ and a magnetic lens which increases the sensitivity of the apparatus. The specimens were pressed against doublesided adhesive tapes mounted on sample holders, and then pumped overnight in the fast-entry lock at $5 \times 10^{-8}$ 
mbar before introduction into the analysis chamber. A $650 \mu \mathrm{m}$ X-ray beam was used at a power of $10 \mathrm{~mA} \times 15$ $\mathrm{kV}$. The spectra were acquired in the constant analyser energy mode, with pass energies of 150 and $40 \mathrm{eV}$ for the survey and the narrow regions, respectively. All samples (powders and plates) were subjected to charge compensation achieved with an electron flood gun combined with an argon ion gun. The argon partial pressure was 2 $\times 10^{-8}$ mbar in the analysis chamber. Avantage software, version 3.51, was used for digital data acquisition and processing. The peak binding energy positions were calibrated by setting the C1s peak maxima to $285.0 \mathrm{eV}$. The apparent surface compositions were determined by considering the integrated areas of the core-level peaks and their respective sensitivity factors.

\section{Results and Discussion}

\subsection{Electrochemical Behaviour of BTA and a BTA-Cu${ }^{2+}$ Complex}

By applying an anodic polarization to the platinum electrode in a $0.1 \mathrm{M}$ TBAP acetonitrile solution of $5 \times 10^{-2}$ M BTA, we obtained cyclic voltammetric curves between 0 and $+1600 \mathrm{mV}$ with an oxidation peak at about $1460 \mathrm{mV}$ (Figure 1(a)). This peak corresponds to the oxidation potential of BTA. As can be seen, only the anodic current intensity increases during the successive potential scans (Figure 1(b)), with a slight shift of the oxidation peak towards positive potentials. This behaviour is due to the formation of a thin film having a short conjugation length (BTA dimer). A similar film can be obtained by applying a constant potential at $1350 \mathrm{mV}$ for 240 s. It is also worth noting, in both the above cases, that the films formed on the electrodes are very adherent, stable, and have a coppery colour.

A similar study was undertaken with the BTA-Cu${ }^{2+}$ complex (chemically synthesized its proposed structure is shown in Schema 1(b)) under the same conditions. The voltammetric behaviour of this complex is characterized, on the first scan, by a shoulder about $1100 \mathrm{mV}$ and a peak at $1360 \mathrm{mV}$ (Figure 2). Compared to the peak of free BTA oxidation (Figure 1), the last peak at 1360 $\mathrm{mV}$ is better defined and a negative shift about $100 \mathrm{mV}$ was observed. These results may be attributed to the oxidation of a BTA-Cu ${ }^{2+}$ complex. In the back-sweep, a wave appears at about $160 \mathrm{mV}$ (see figure insert), tentatively assigned to copper reduction in the BTA-Cu ${ }^{2+}$ complex. On the second scan, a large wave at about 350 $\mathrm{mV}$ corresponds to copper oxidation and the oxidation peak observed at $1360 \mathrm{mV}$ disappears. Surprisingly, during successive potential cyclic sweeps between -100 and $1600 \mathrm{mV}$ (Figure 2) in a BTA-Cu${ }^{2+}$ complex solution, no film is formed on the Pt electrode, contrary to the case of free BTA.

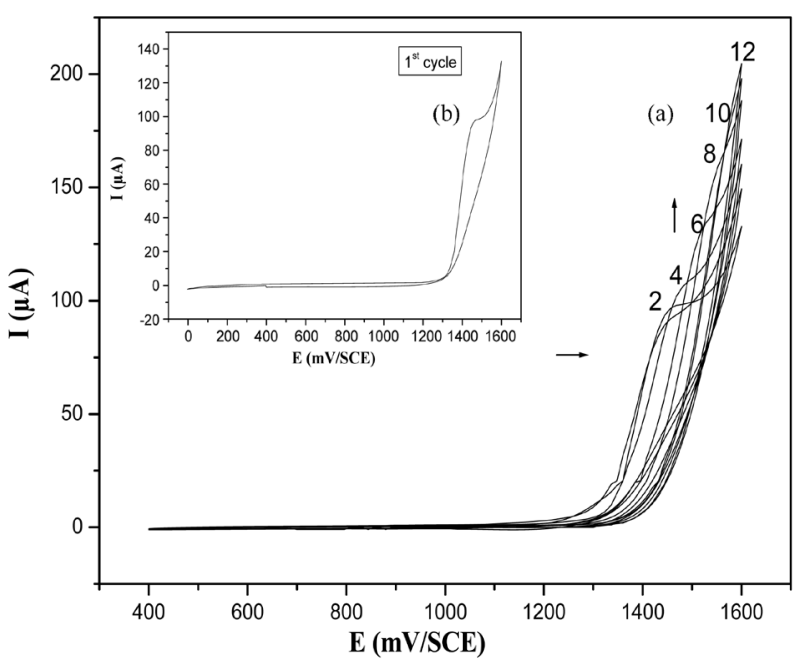

Figure 1. Cyclic voltammograms of BTA $5 \times 10^{-2} \mathrm{M}$ in 0.1 $\mathrm{M} \mathrm{TBAP} / \mathrm{CH}_{3} \mathrm{CN}$ at Pt electrode. Scan rate $=50 \mathrm{mV} \cdot \mathrm{s}^{-1}$. (a) first cycle recorded in $0-1600 \mathrm{mV}$ range, (b) repetitive scans between 400 and $1600 \mathrm{mV}$.

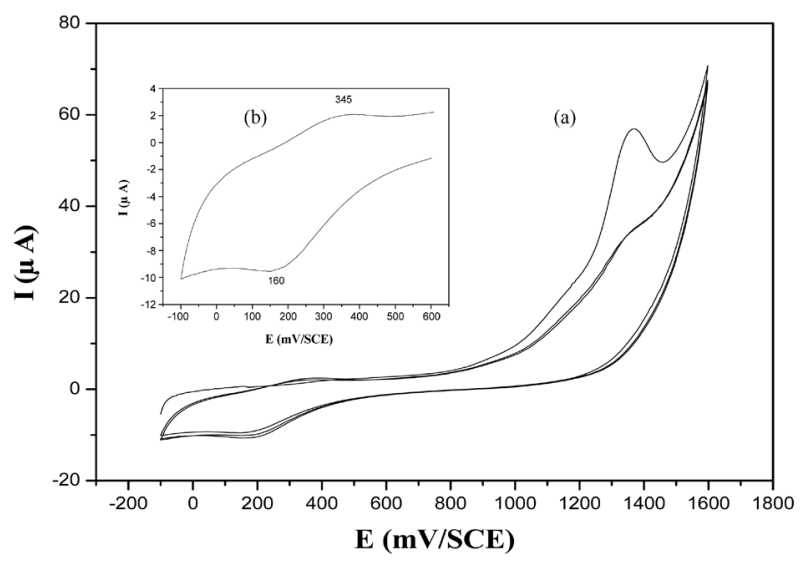

Figure 2. Cyclic voltammogram of $\mathrm{BTA}-\mathrm{Cu}^{2+}$ complex in 0.1 $\mathrm{M}$ TBAP/CH $/ \mathrm{CH}_{3} \mathrm{CN}$ at a Pt electrode at $50 \mathrm{mV} \cdot \mathrm{s}^{-1}$.

\subsection{Characterization of Free BTA Film and BTA Film-Cu ${ }^{2+}$ Complex}

\subsubsection{Electrochemical Characterization}

Thin films freshly prepared either by cyclic voltammetry or by the potentiostatic method were cycled in $\mathrm{CH}_{3} \mathrm{CN}$ containing $0.1 \mathrm{M}$ TBAP or in $\mathrm{H}_{2} \mathrm{O}$ containing $0.1 \mathrm{M} \mathrm{Li}-$ $\mathrm{ClO}_{4}$ to study their electrochemical behaviour. In both cases, these films present no redox peaks in the range of potential from 0 to $1600 \mathrm{mV}$ (Figure 3(a)), indicating that there is no electroactivity corresponding to the doping-dedoping of these films.

Despite the lack of electroactivity in both the above solutions, the BTA dimer films having carboxylic functional groups are able to complex electroactive species such as $\mathrm{Cu}^{2+}, \mathrm{Co}^{2+}$ and $\mathrm{Ag}^{+}$, which allow them to be used as sensors. These films were immersed in aqueous solutions containing either $\mathrm{Cu}^{2+}$ or $\mathrm{Co}^{2+}$ for $10 \mathrm{~min}$, then 
rinsed with water and transferred to an electrochemical cell containing either $\mathrm{CH}_{3} \mathrm{CN}+0.1 \mathrm{M}$ TBAP or water + $0.1 \mathrm{M} \mathrm{LiClO}_{4}$.

In the first case, the cyclic voltammogram (CV) displayed oxidation and reduction peaks at 590 and $340 \mathrm{mV}$ (Figure 3(b)), respectively. In addition, the difference between the oxidation and reduction potentials, $\Delta E_{p}=$ $255 \mathrm{mV}$, showed that the process is irreversible and the ratio of anodic to cathodic peak currents (Ipc/Ipa $=1)$ corresponds to a one-electron process. These results can be attributed to the $\mathrm{Cu}^{2+} / \mathrm{Cu}^{+}$redox couple incorporated (trapped or complexed) [22] into the BTA films.

In the second case, similar observations to those of the first case were observed, but the two redox peaks shifted to more negative potentials, at 100 and $-100 \mathrm{mV}$, respectively (Figure 4). Moreover, when the electroactivity of BTA thin-films after immersion in $\mathrm{CuCl}_{2}$ solution was tested in an aqueous solution of $0.1 \mathrm{M} \mathrm{LiClO}_{4}$, a drastic change in the $\mathrm{CV}$ features was observed. The related CV shows behaviour similar to that observed for $\mathrm{CuCl}_{2}$ in aqueous solution, consisting of electrochemically irreversible redox peaks $\mathrm{Cu}^{2+} / \mathrm{Cu}^{+}$at ca. +100 and $-100 \mathrm{mV}$. It is interesting to note that these peaks shift to more negative potentials compared to that obtained in $\mathrm{CH}_{3} \mathrm{CN}$ and have good electrochemical stability under repetitive cyclic voltammetry. These results, in aqueous solution, imply that the BTA film- $\mathrm{Cu}^{2+}$ has rather good electrochemical stability, is more electroactive and has high porosity, which is necessary to allow the oxidation-reduction of $\mathrm{Cu}^{2+}$ complexing or trapping with BTA dimer films.

A similar study was carried out by immersing BTA thin-films in an aqueous solution of $\mathrm{CoCl}_{2}$ or $\mathrm{AgNO}_{3}$. The redox properties of BTA thin-film- $\mathrm{Co}^{2+}$ or BTA thin-film- $\mathrm{Ag}^{+}$in aqueous solution exhibit features similar to those observed for BTA thin-film- $\mathrm{Cu}^{2+}$ (data not shown), which confirms the presence of metallic ions in BTA thin-films [23-25].

\subsubsection{XPS Spectra Analysis}

To verify and confirm the presence of metal ions in the BTA thin-films, XPS measurements were carried out on the free BTA thin-film, BTA thin-film- $\mathrm{Cu}^{2+}$ and BTA$\mathrm{Cu}^{2+}$ complex powder chemically prepared.

The survey spectra of a BTA thin-film and after its immersion in a $0.1 \mathrm{M} \mathrm{CuCl}_{2}$ solution for $10 \mathrm{~min}$ are shown in Figure 5. All the expected elements such as C1s, O1s, S2p in the polymer film can be seen (Figure 5(a)). Additional peaks can be detected in BTA thin-film- $\mathrm{Cu}^{2+}$ at 935.2 and $955.0 \mathrm{eV}$ corresponding to $\mathrm{Cu} 2 \mathrm{p}_{3 / 2}$ and $2 \mathrm{p}_{1 / 2}$ (Figure 5(b)), respectively, which indicates that $\mathrm{Cu}^{2+}$ species present in the BTA-Cu${ }^{2+}$ complex-modified surface. However, it is interesting to note that similar peaks at the same binding energies are observed in the

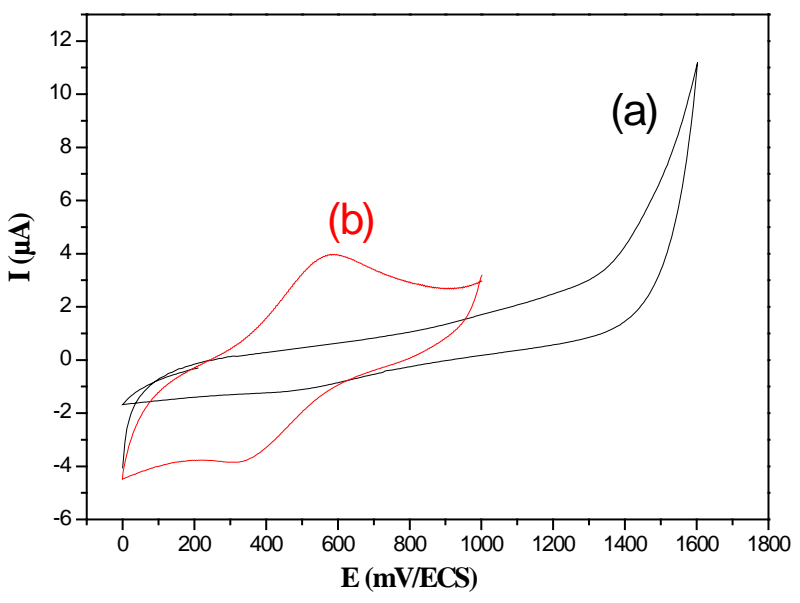

Figure 3. Cyclic voltammogram of BTA- $\mathrm{Cu}^{2+}$ complex in 0.1 $\mathrm{M}$ TBAP/CH $/ \mathrm{CH}_{3} \mathrm{CN}$ at a Pt electrode at $50 \mathrm{mV} \cdot \mathrm{s}^{-1}$.

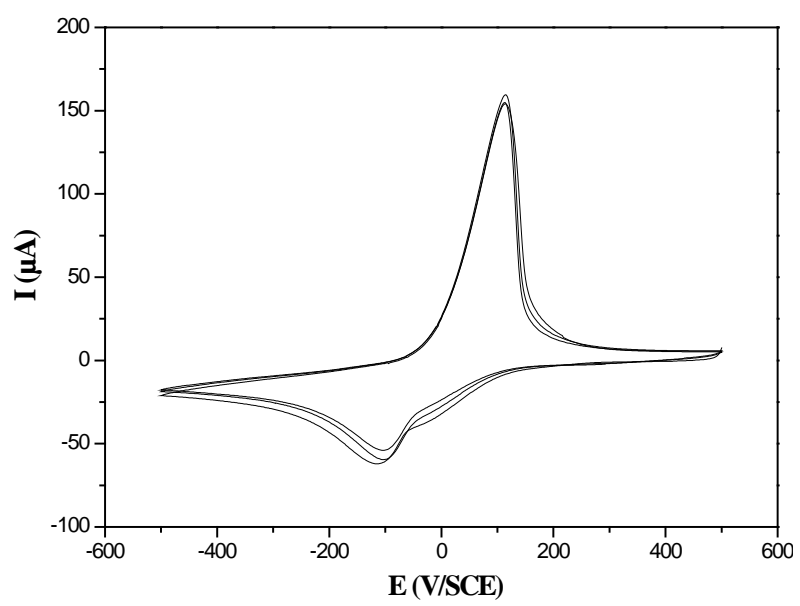

Figure 4. Cyclic voltammogram of BTA thin-film- $\mathrm{Cu}^{2+}$ in $0.1 \mathrm{M} \mathrm{LiClO}_{4} / \mathrm{H}_{2} \mathrm{O}$ at $100 \mathrm{mV} \cdot \mathrm{s}^{-1}$.

case of a BTA-Cu ${ }^{2+}$ complex powder. These results suggest that $\mathrm{Cu}^{2+}$ is complexed by BTA thin-film. In addition, when comparing the binding energy (BE) values of the O1s in BTA and BTA film- $\mathrm{Cu}^{2+}$, we note that the oxygen $\mathrm{BE}$ is shifted about $0.8 \mathrm{eV}$ (from 532.5 to 531.7 $\mathrm{eV}$ ) due to O-Cu bonding [26], resulting probably from the complexation of a $-\mathrm{COO}^{-}$functional group of BTA with $\mathrm{Cu}^{2+}$. This observation was confirmed below by IR spectroscopy.

Similar XPS analysis were performed on BTA thinfilm- $\mathrm{Ag}^{+}, \mathrm{BTA}$ thin-film- $\mathrm{Co}^{2+}$ and on the corresponding complexes under form of powders. These analyses reveal the presence of $\mathrm{Ag}^{+}$and $\mathrm{Co}^{2+}$ in the BTA thin-films and powder complexes (data not shown). In our study, the detection of an O-Cu bond by XPS spectrum confirmed the formation of the BTA-Cu${ }^{2+}$ complex [27].

\subsubsection{IR Spectra}

IR measurements were performed on the ligand (BTA), BTA film- $\mathrm{Cu}^{2+}$ deposited on an ITO electrode and a 

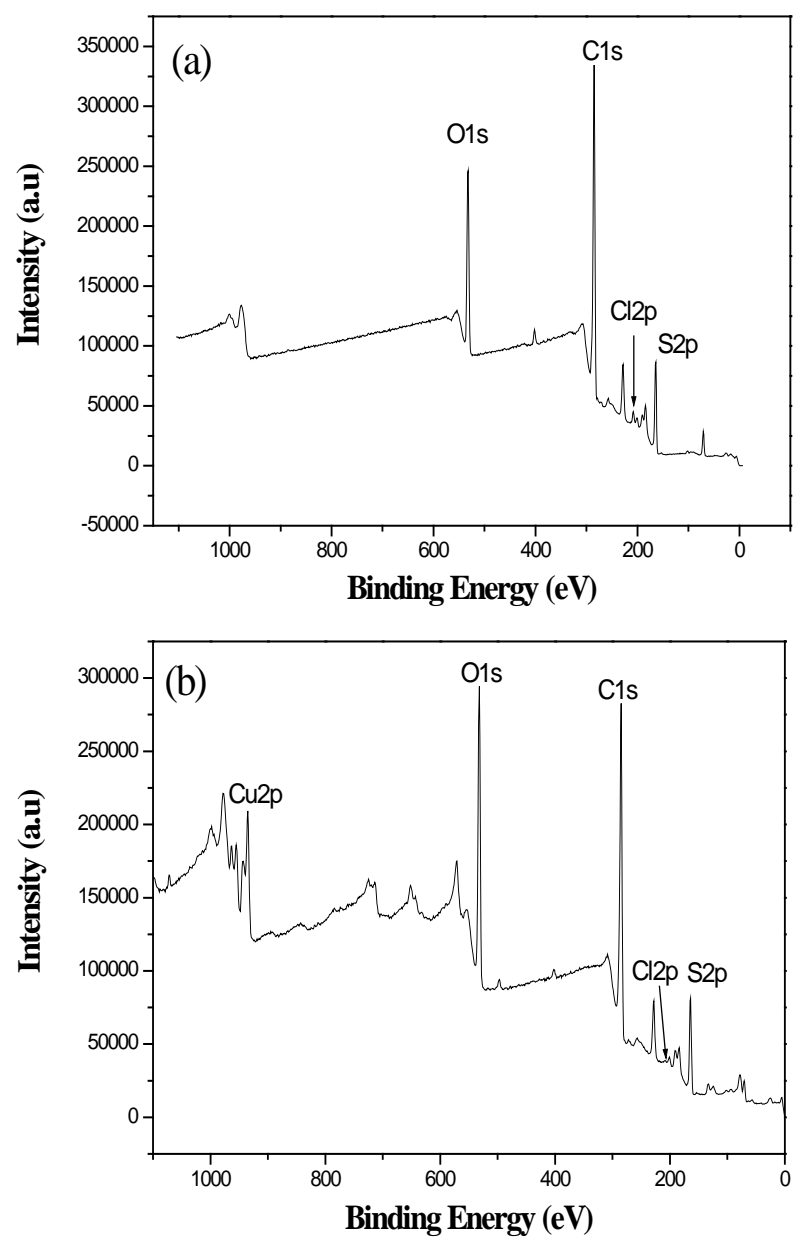

Figure 5. XPS survey spectra of: (a) BTA thin-film and (b) BTA thin-film after immersion in $0.1 \mathrm{M} \mathrm{CuCl}_{2}$ solution for 5 min.
BTA-Cu${ }^{2+}$ powder. By comparing the IR frequencies of the free ligand with those of BTA film- $\mathrm{Cu}^{2+}$ and BTA$\mathrm{Cu}^{2+}$ powder can be highlighted the formation of the complex (Figure 6). It is interesting to note that there are differences between the main characteristic absorp- tion peaks of these materials and that of the ligand. The strong band at $1673 \mathrm{~cm}^{-1}$ corresponding to $v(\mathrm{C}=\mathrm{O})$ stretching vibration of $\mathrm{COOH}$ in the free ligand (Figure 6(a)) disappears and new very strong and sharp bands in the 1550 - 1510 and $1450-1400 \mathrm{~cm}^{-1}$ regions corresponding to the asymmetric and symmetric vibrations of the $-\mathrm{COO}^{-}$group, respectively, appear in the BTA film$\mathrm{Cu}^{2+}$ and BTA-Cu${ }^{2+}$ powder (Figure 6(b)). These results clearly show $\mathrm{COOH}$ functional group deprotonation and coordination to a $\mathrm{Cu}^{2+}$ [28-30]. In addition, a broad, weak band at $3358 \mathrm{~cm}^{-1}$ observed in BTA film- $\mathrm{Cu}^{2+}$ and $\mathrm{BTA}-\mathrm{Cu}^{2+}$ powder is attributed to $v_{\mathrm{OH}}$ of the methanol or water involved in the BTA-Cu${ }^{2+}$ structure [21,31,32]. The bands at 813 and $777 \mathrm{~cm}^{-1}$ are assigned to C-S bond vibrations.

\subsection{Electrocatalytic Behaviour of BTA Thin-Film-Metal Ion Complexes toward Ascorbic Acid}

Many compounds have been found to be active electron transfer mediators of the electocatalytic oxidation of ascorbic acid (AA) [13,33,34]. In our case also, the electrocatalytic behaviour of BTA thin-film modified by ion metals has been studied toward ascorbic acid oxidation in a 0.1 M phosphate buffer at $\mathrm{pH}$ 7.4.

BTA thin-films were immersed for $10 \mathrm{~min}$ in various solutions containing $\mathrm{CuCl}_{2}, \mathrm{CoCl}_{2}$ and $\mathrm{AgNO}_{3}$; then the electrode was removed, rinsed with distilled water and

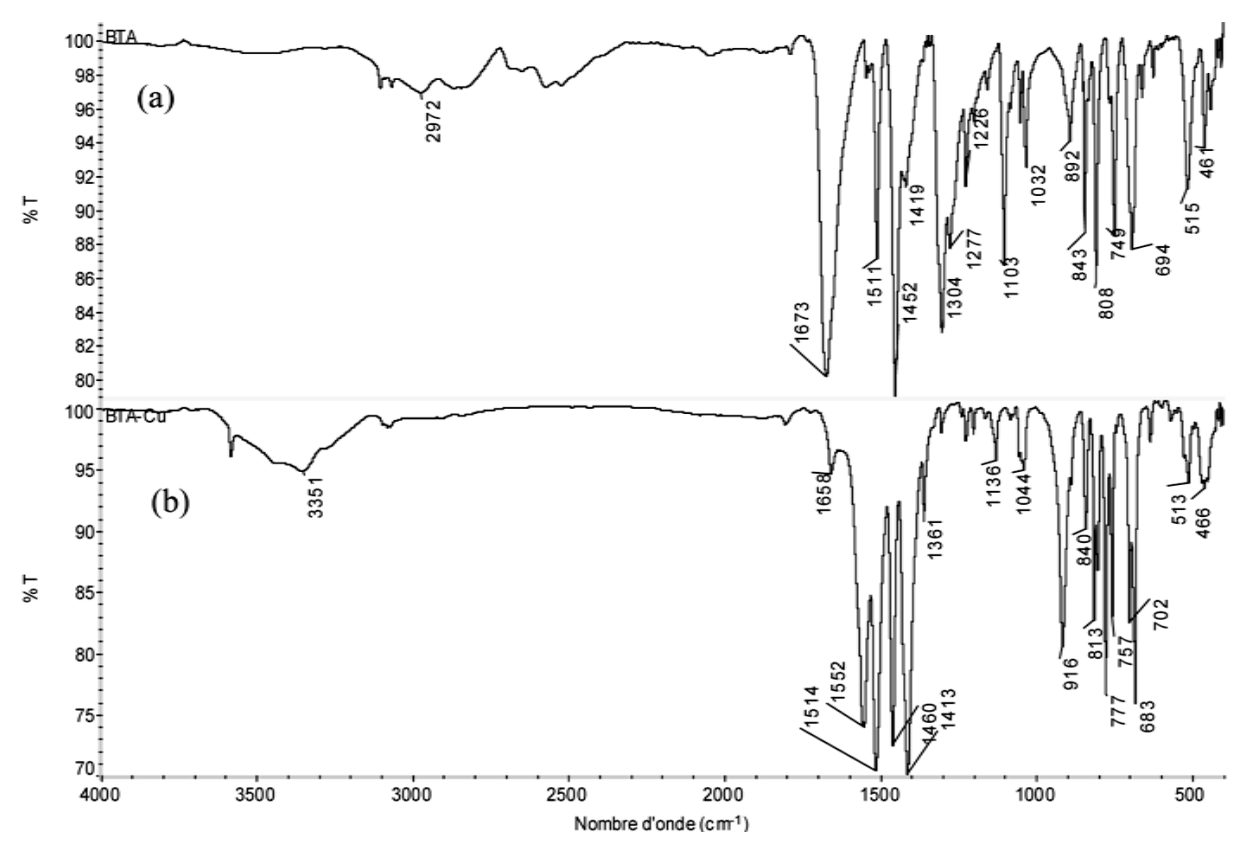

Figure 6. FTIR spectra of: (a) BTA; (b) BTA-Cu ${ }^{2+}$ complex. 
transferred to a freshly prepared ascorbic acid solution. Cyclic voltammetry was used to examine the electroactivity of BTA thin-film-metal ion complexes deposited on Pt electrodes. The cyclic voltammograms of $0.1 \mathrm{M}$ phosphate buffer containing $5 \mathrm{mM}$ of AA clearly show (Figure 7) that BTA thin-film-metal ion complexes present good electrocatalytic activity toward AA compared to that obtained on a free BTA thin-film.

As shown in Figure 7, there is no peak corresponding to the oxidation of AA on a free BTA film (Figure 7(a)). However, irreversible oxidation peaks at ca. 126, 285 and $306 \mathrm{mV}$ were obtained on BTA thin-film- $\mathrm{Cu}^{2+}$, BTA thin-film- $\mathrm{Ag}^{+}$and BTA thin-film- $\mathrm{Co}^{2+}$, respectively, corresponding to AA oxidation. These results suggest that the metal ion plays an intermediate to transport the electron transfer between AA and the BTA thin-film electrode. It should be noted that the oxidation peak current on BTA thin-film- $\mathrm{Ag}^{+}$is approximately twice that on BTA thin-film- $\mathrm{Cu}^{2+}$ and BTA thin-film- $\mathrm{Co}^{2+}$. This finding reveals that the catalytic activity of $\mathrm{Ag}^{+}$complexed with BTA thin-film is the best toward AA oxidation and BTA thin-film- $\mathrm{Ag}^{+}$can be detected a very low concentration of AA in a solution $(\sim 1 \mu \mathrm{M})$. In contrast, the oxidation of AA on BTA thin-film- $\mathrm{Cu}^{2+}$ was shifted to negative potential about $200 \mathrm{mV}$ compared to that at BTA thin-film- $\mathrm{Co}^{2+}$. This result suggests that electron transfer between AA and BTA thin-film by the intermediary of $\mathrm{Cu}^{2+}$ is easier than that by $\mathrm{Co}^{2+}$.

\section{Conclusion}

In this work, we have prepared and characterized BTA films deposed electrochemically on Pt electrodes. We have shown that these films after immersing in metal ion

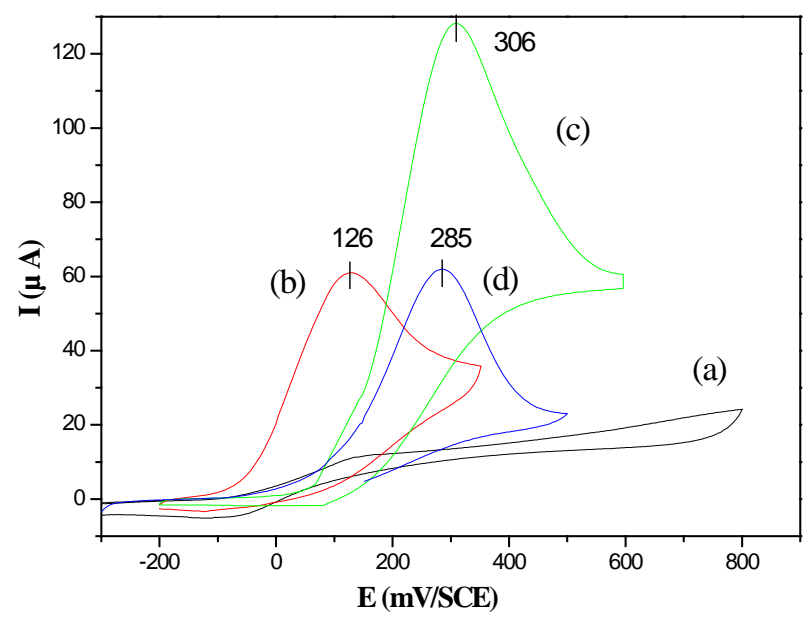

Figure 7. Comparison of the CV responses for $5 \mathrm{mM}$ AA in phosphate buffer solution (0.1 M PBS, pH 7.4) at various modified electrodes: (a) BTA thin-film; (b) BTA thin-film$\mathrm{Cu}^{2+}$; (c) BTA thin-film- $\mathrm{Ag}^{+}$and (d) BTA thin-film-Co ${ }^{2+}$; v $=100 \mathrm{mV} \cdot \mathrm{s}^{-1}$. solutions such as $\mathrm{Cu}^{2+}, \mathrm{Ag}^{+}$or $\mathrm{Co}^{2+}$ had an electrocatalytic process for AA oxidation as analyte. This electrocatalytic activity toward such an analyte is particularly interesting owing to the fundamental importance for several applications, especially in the pharmaceutical and food fields. Moreover, we have shown by spectroscopic techniques (IR, XPS) that BTA can form a complex with $\mathrm{Cu}^{2+}, \mathrm{Ag}^{+}$or $\mathrm{Co}^{2+}$, and that these metallic ions remain in the film after its use as an electrode in the reaction of AA oxidation. These electrodes may be used as sensors for the detection of AA.

\section{REFERENCES}

[1] G. Tourillon, "Handbook of Conducting Polymers,” Marcel Dekker, New York, 1986.

[2] J. Roncali, "Conjugated Poly(thiophenes): Synthesis, Functionalization, and Applications," Chemical Reviews, Vol. 92, No. 4, 1992, pp. 711-738. http://dx.doi.org/10.1021/cr00012a009

[3] R. C. Martinez, F. B. Dominguez, F. M. Gonzalez, J. H. Mendez and R. C. Orellana, "Polypyrrole-Dodecyl Sulphate Electrode as a Microsensor for Electroinactive Cations in Flow-Injection Analysis and Ion Chromatography,” Analytica Chimica Acta, Vol. 279, No. 2, 1993, pp. 299-307. http://dx.doi.org/10.1016/0003-2670(93)80330-N

[4] V. Tsakova and A. Milchev, "Electrochemical Formation and Stability of Polyaniline Films," Electrochimica Acta, Vol. 36, No. 5-6, 1991, pp. 1151-1155. http://dx.doi.org/10.1016/0013-4686(91)85102-D

[5] M. Gholamian and A. Q. Contractor, "Oxidation of Formic Acid at Platinum Microparticles Dispersed in a Polyaniline Matrix," Journal of Electroanalytical Chemistry, Vol. 289, No. 1-2, 1990, pp. 69-83. http://dx.doi.org/10.1016/0022-0728(90)87207-Z

[6] H. Laborde, J. M. Léger and C. Lamy, "Electrocatalytic Oxidation of Methanol and C1 Molecules on Highly Dispersed Electrodes," Journal Applied Electrochemistry, Vol. 24, 1994, pp. 219-26.

[7] M. Umana and J. Waller, "Protein Modified Electrodes: The Glucose Oxidase/Polypyrrole System,” Analytical Chemistry, Vol. 58, No. 14, 1986, pp. 2979-2983. http://dx.doi.org/10.1021/ac00127a018

[8] I. Marawi, A. Khaskelis, A. Galal, J. F. Rubinson, R. P. Popat, F. J. Boerio and H. B. Mark, "Metal Ion Incorporation in the Conducting Polymer Electrode Matrix Using an 'Active' Metal Substrate," Journal of Electroanalytical Chemistry, Vol. 434, No. 1-2, 1997, pp. 61-68. http://dx.doi.org/10.1016/S0022-0728(97)00059-4

[9] J. L. Reddinger and J. R. Reynolds, "Electroactive, PiConjugated Polymers Based on Transition Metal-Containing Thiophenes," Synthetic Metals, Vol. 84, No. 1-3, 1997, pp. 225-226. http://dx.doi.org/10.1016/S0379-6779(97)80724-2

[10] K. Sonogashira, S. Kakahashi and N. Hagihara, "A New Extended Chain Polymer, Poly [Trans-bis(tri-n-butylpho- 
sphine)platinum1,4-butadiynediyl]," Macromolecules, Vol. 10, No. 4, 1977, pp. 879-880.

http://dx.doi.org/10.1021/ma60058a037

[11] A. Malinauskas, "Electrocatalysis at Conducting Polymers,” Synthetic Metals, Vol. 107, No. 2, 1999, pp. 75-83. http://dx.doi.org/10.1016/S0379-6779(99)00170-8

[12] F. Beck, E. Abdelmula and M. Dahlhaus, “Anodische Abscheidung von Polypyrrol/Ruß- und Polythiophen/ Ruß-Composites," GDCh-Monographie, Vol. 3, 1996, pp. 524-535.

[13] A. Sivanesan, P. Kannan and S. J. Abraham, "Electrocatalytic Oxidation of Ascorbic Acid Using a Single Layer of Gold Nanoparticles Immobilized on 1,6-Hexanedithiol Modified Gold Electrode,” Electrochimica Acta, Vol. 52, No. 28, 2007, pp. 8118-8124. http://dx.doi.org/10.1016/j.electacta.2007.07.020

[14] H. X. Wu, S. Q. Dong, J. W. Kang and X. Q. Lu, "Electrochemical Behavior of Ascorbic Acid on Hexaaza Macrocyclic Copper(II) Complex Modified Au Electrode and Its Analytical Application," Chinese Journal of Chemistry, Vol. 26, No. 10, 2008, pp. 1893-1898. http://dx.doi.org/10.1002/cjoc.200890340

[15] J. B. Raoof, R. Ojani and H. Beitollahi, "Electrocatalytic Determination of Ascorbic Acid at Chemically Modified Carbon Paste Electrode with 2, 7-bis (Ferrocenyl ethynyl) Fluoren-9-one," International Journal of Electrochemistry Science, Vol. 2, No. 7, 2007, pp. 534-548.

[16] M. K. Motlagh and M. Noroozifar, "Electrocatalytic Determination of Ascorbic Acid Using Glassy Carbon Modified with Nickel(II) Macrocycle Containing Dianionic Tetraazaannulene Ligand," Turkish Journal of Chemistry, Vol. 28, No. 3, 2004, pp. 369-378.

[17] S. A. Kumar, P. H. Lo and S. M. Chen, "Electrochemical Selective Determination of Ascorbic Acid at Redox Active Polymer Modified Electrode Derived from Direct Blue 71,” Biosensors and Bioelectronics, Vol. 24, No. 4, 2008, pp. 518-523.

http://dx.doi.org/10.1016/j.bios.2008.05.007

[18] S. Hou, N. Zheng, H. Feng, X. Li and Z. Yuan, "Determination of Dopamine in the Presence of Ascorbic Acid Using Poly(3,5-dihydroxy benzoic acid) Film Modified Electrode,” Analytical Biochemistry, Vol. 381, No. 2, 2008, pp. 179-184. http://dx.doi.org/10.1016/j.ab.2008.03.055

[19] F. Zhu, J. Yan, C. Sun, X. Zhang and B. Mao, “An Electrochemical Method for Selective Detection of Dopamine by Depleting Ascorbic Acid in Diffusion Layer,” Journal Electroanalytical Chemistry, Vol. 640, No. 1-2, 2010, pp. 51-56. http://dx.doi.org/10.1016/j.jelechem.2010.01.006

[20] M. Moreno, A. S. Arribas, E. Bermejo, M. Chicharro, A. Zapardiel, M. Rodríguez, Y. Jalit and G. Rivas, "Selective Detection of Dopamine in the Presence of Ascorbic Acid Using Carbon Nanotube Modified Screen-Printed Electrodes,’' Talanta, Vol. 80, No. 5, 2010, pp. 2149-2156. http://dx.doi.org/10.1016/j.talanta.2009.11.022

[21] D. Panagoulis, E. Pontiki, E. Skeva, C. Raptopoulou, S. Girousi, L. D. Hadjipavlou and S. C. Dendrinou, "Synthesis and Pharmacochemical Study of New Cu(II) Complexes with Thiophen-2-yl Saturated and $\alpha, \beta$-Unsaturated
Substituted Carboxylic Acids," Journal of Inorganic Biochemistry, Vol. 101, No. 4, 2007, pp. 623-634. http://dx.doi.org/10.1016/j.jinorgbio.2006.12.004

[22] P. V. Bernhardt and N. L. Kilah, "Macrocyclic Cobalt(III) Complexes as Precursors for Metal-Polythiophene Hybrid Materials,” Polyhedron, Vol. 26, No. 2, 2007, pp. 392399. http://dx.doi.org/10.1016/j.poly.2006.07.001

[23] G. G. Wallace, H. Zhao, C. O. Too and C. J. Small, "Novel Conducting Polymer-Polyelectrolyte Composites," Synthetic Metals, Vol. 84, No. 1-3, 1997, pp. 323-326. http://dx.doi.org/10.1016/S0379-6779(97)80766-7

[24] K. Takeshita, W. Wernet and N. Oyama, "Electrochemical Quartz Crystal Microlabalance Investigation of a Poly (pyrrole)/Sulphated Poly(b-hydroxyether) Composite Film," Journal Electrochemistry Society, Vol. 141, No. 8, 1994, pp. 2004-2009. http://dx.doi.org/10.1149/1.2055050

[25] B. Ballarin, R. Seeber, L. Tassi and D. Tonelli, "Electrochemical Synthesis and Characterisation of Polythiophene Conducting Polymers Functionalised by Metal-Containing Porphyrin Residue,” Synthetic Metals, Vol. 114, 2002, pp. 79-285.

[26] B. Wang, F. Gao and H. Ma, "Preparation and XPS Studies of Macromolecule Mixed-Valent Cu(I, II) and Fe(II, III) Complexes,” Journal Hazardous Material, Vol. 144, No. 1-2, 2007, pp. 363-368. http://dx.doi.org/10.1016/j.jhazmat.2006.10.043

[27] M. A. Rahman, K. S. Lee, D. S M. Park, S. Won and Y. B. Shim, "An Amperometric Bilirubin Biosensor Based on a Conductive Poly-Terthiophene-Mn(II) Complex,” Biosensors and Bioelectronics, Vol. 23, No. 8, 2008, pp. 857864. http://dx.doi.org/10.1016/j.bios.2007.09.005

[28] M. Ignatova, M. Sepulchre and N. Mnolova, "Synthesis, Characterisation and Complex Forming Ability towards Ferric Ions of Oligo(ether-amide)s of Jeffamines ED'R) and Chelidamic Acid,” Journal European Polymer, Vol. 38, No. 1, 2002, pp. 33-38. http://dx.doi.org/10.1016/S0014-3057(01)00178-1

[29] G. Socrates, "Infrared and Raman Characteristic Group Frequencies: Tables and Charts,” 3rd Edition, Wiley, Chichester, 2001.

[30] H. L. Gao, L. Yi, B. Zhao, X. Q. Zhao, P. Cheng, D. Z. Liao and S. P. Yan, "Synthesis and Characterization of Metal-Organic Frameworks Based on 4-Hydroxypyridine-2,6-dicarboxylic Acid and Pyridine-2,6-dicarboxylic Acid Ligands,” Inorganic Chemistry, Vol. 45, No. 15, 2006, pp. 5980-5988. http://dx.doi.org/10.1021/ic060550j

[31] M. Rusu, L. David, A. Marcu, D. Rusu and A. Stănilă, "Spectroscopic Studies of Some Copper(II) Complexes with Amino Acids,” Journal of Molecular Structure, Vol. 834-836, 2007, pp. 364-368. http://dx.doi.org/10.1016/j.molstruc.2006.11.048

[32] F. Karipcin, B. Dede, Y. Caglar, D. Hür, S. Ilican, M. Caglar and Y. Şhain, "A New Dioxime Ligand and Its Trinuclear Copper (II) Complex: Synthesis, Characterisation and Optical Properties," Optics Communications, Vol. 272, No. 1, 2007, pp. 131-140. http://dx.doi.org/10.1016/j.optcom.2006.10.079

[33] D. R. Shankaran, K. Iimura and T. Kato, "Simultaneous Determination of Ascorbic Acid and Dopamine at a Sol- 
Gel Composite Electrode,” Sensors Actuators B, Vol. 94, No. 1, 2003, pp. 73-80.

http://dx.doi.org/10.1016/S0925-4005(03)00327-7

[34] H. Wang, Y. Huang, Z. Tan and X. Hu, "Fabrication and
Characterization of Copper Nanoparticle Thin-Films and the Electrocatalytic Behavior," Analytica Chimica Acta, Vol. 526, No. 1, 2004, pp. 13-17.

http://dx.doi.org/10.1016/j.aca.2004.08.060 